\title{
The Analysis and Research on Cost Advantages of Ships Sailing on Arctic NEP
}

\author{
Li Ning \\ Department of Navigational Technology, Merchant Marine College, Shanghai Maritime University, Shanghai 201306, P.R. China
}

\begin{abstract}
The cost advantage of Arctic NEP (Northeast Passage) is mainly analyzed. The traditional southern route through the Suez Canal between the East Asia and the Europe is referred as benchmark route, general cargo ship and container ship are respectively selected as benchmark ships, which are analyzed and compared with Arctic NEP from fuel consumption, insurance, icebreaker fees and cost for SOLAS amendment, etc. The study reveals that Arctic NEP highly reduces general cargo ships' sailing time, container ships' fuel consumption, and contributes to shipping's sustainable development.
\end{abstract}

Key words: Arctic NEP, cost advantages, shipping, analysis and research, sustainable development.

\section{Introduction}

In recent years, the opening of Arctic NEP (Northeast Passage) in summer makes the maritime transport from east Asia to Europe more fast, economic, and brings great convenience for east-west trade and development of world economy. With global warming, the melting speed of the Arctic sea ice is accelerating. The latent traffic strategic value in the Arctic area has become increasingly prominent: the NEP connecting the Atlantic Ocean and the Pacific Ocean is becoming navigable throughout the year at a very fast speed [1].

Once the Arctic sea ice melts totally, the Arctic NEP will be completely navigable and significantly change the world pattern of economy, trade and maritime transport. The north of our country is located within the extension of the Arctic NEP, so the changed of the Arctic NEP are closely related to China, especially the shipping industry of our country. This paper takes the Arctic NEP as the research object comparing with the traditional passage via the Suez Canal, and analyzes the commercial value of the Arctic NEP [2-5].

Corresponding author: Li Ning, lecturer, research fields: transportation information engineering \& control.

\section{Research Method}

The purpose of this paper is to look at the commercial aspects of using NEP to a similar trip using the Suez Canal. There are many ways one could make comparisons, but the main three usual approaches are:

- Calculating the total transportation costs for using each route to obtain a \$/ton cost estimate for each route;

- Calculating the total cost of setting up a regular service based on an assumed yearly quantity to be shipped;

- Focusing on cost differences among the route alternatives.

The first approach focuses on cost savings for the end user of transport. The second approach takes into consideration that saving time makes it possible to service a given amount of cargo with fewer vessels (trips) and is thus taking into consideration the capital costs of investing in vessels. The third approach is more used in a first commercial feasibility study, i.e. one explores the order of magnitude of cost savings to get a feeling for cost differences and to be able to do simple sensitivity tests.

Since this paper is considering a hypothetical future where ice conditions have greatly changed in the 
Arctic, the starting point for a comparison will be to assume Arctic transit without icebreaker support. By then calculating the cost advantage of the northerly routes vs. a southern route through the Suez Canal, the implicit willingness to pay for icebreaker support will also be given.

The research therefore uses the third approach and looks at the main cost components where there will be differences. The comparison would be relevant for a ship owner with a given ship and a choice of which route to sail. So general ship and container ship are recognized as the typical type of ship, and the routes between the Far East area and the Europe are taken as the typical routes. The benchmark ships and routes are as follows:

- Benchmark ships: general ship: Beluga Fraternity (sailing in the Arctic northeast passage in September 2009) and her sister ship; container ship: CSCL Hamburg;

- Benchmark routes: Yokohama to Hamburg via Suez; Shanghai to Hamburg via Suez;

- Arctic NEP: Yokohama-Hamburg via NEP; Shanghai-Hamburg via NEP.

\section{Costs Analysis on Benchmark Routes}

\subsection{Yokohama to Hamburg via Suez}

The main data for benchmark general ship are given by IHS in Table 1.

The route specific data are given in Table 2.

The Suez Canal toll has been calculated on the basis of the calculator provided by the Suez Canal authorities, using current exchange rates for SDR5/\$.

The insurance figures are based on figures from Drewry [6], where yearly figures have been converted to $\$$ /day figures. The comparison of insurance costs is, however, a tricky one. Currently the insurance costs for ships passing the Gulf of Aden towards Suez have soared since 2008 due to the piracy risk. It is claimed that the insurance has increased tenfold for this coastal area between September 2008 and March 2009. After 2015, if the situation of the globe shipping market
Table 1 General cargo ship characteristics.

\begin{tabular}{|l|l|}
\hline Gross tonnage GRT & 9,611 \\
\hline Net tonnage NRT & 4,260 \\
\hline Deadweight ton DWT & 12,672 \\
\hline Suez Canal Net Tonnage SCNT & 12,915 \\
\hline Draught in meter & 8 \\
\hline Service speed in knots & 14 \\
\hline Gram fuel per kwh & 190 \\
\hline Power in kw & 5,400 \\
\hline Ton fuel per day at service speed & 24.624 \\
\hline
\end{tabular}

Table 2 Route specific data Yokohama-Hamburg via Suez.

\begin{tabular}{|l|l|}
\hline Distance in nautical miles (nm) & 11,430 \\
\hline Journey days at service speed & 34 \\
\hline Fuel consumption in tons & 838 \\
\hline Suez canal toll in \$ & 51,168 \\
\hline Hull and machinery insurance \$/day & 360 \\
\hline $\begin{array}{l}\text { P\&I } \\
\text { P\&I insurance, \$/day }\end{array}$ & 340 \\
\hline
\end{tabular}

persists like now, the shipping costs will maintain the present level, such as insurance cost. On the contrary, if the insurance cost raises dramatically, it will increase the advantage of Arctic passages. It is claimed this is one important motivating factor for China's increased interest in the Arctic [2-4].

\subsection{Shanghai to Hamburg via Suez}

As the benchmark container ship, CSCL Hamburg with a capacity over 4,000 TEU, main ship data are given by IHS in Table 3.

The route specific data are given in Table 4.

\section{Increased Costs of Ships Sailing on Arctic NEP by SOLAS Amendment}

\section{SOLAS Chapter XIV "SAFETY MEASURES FOR} SHIPS OPERATING IN POLAR WATERS” includes the requirements about ship structure and machinery, manning and training, navigation and communication, fire safety and life-saving appliance and arrangements for ships sailing in the polar waters $[7,8]$.

- ships shall be ice strengthened [7, 8];

- ships constructed on or after 1 July 2017, ice strengthened shall have either two independent echo-sounding devices or one echo-sounding device with 
Table 3 Container vessel data.

\begin{tabular}{|l|l|}
\hline Gross tonnage GRT & 39,941 \\
\hline Net tonnage NRT & 24,458 \\
\hline Deadweight ton DWT & 50,790 \\
\hline TEU & 4,253 \\
\hline Suez Canal Net Tonnage SCNT & 57,387 \\
\hline Draught in meter & 12.6 \\
\hline Service speed & 23 \\
\hline Gram fuel per kwh & 190 \\
\hline Power in kw & 36,515 \\
\hline Ton fuel per day at service speed & 166.5 \\
\hline
\end{tabular}

Table 4 Route specific data Shanghai-Hamburg via Suez.

\begin{tabular}{|l|l|}
\hline Distance in nautical miles (nm) & 10,857 \\
\hline Journey days at service speed & 20 \\
\hline Fuel consumption in tons & 3,275 \\
\hline Suez canal toll in \$ & 135,145 \\
\hline Hull and machinery insurance \$/day & 750 \\
\hline P\&I insurance, \$/day & 460 \\
\hline
\end{tabular}

two separate independent transducers [7, 8];

- ships shall have two non-magnetic means to determine and display their heading. Both means shall be independent and shall be connected to the ship's main and emergency source of power [7, 8];

- ships proceeding to latitudes over 80 degrees shall be fitted with at least one GNSS compass or equivalent, which shall be connected to the ship's main and emergency source of power [7, 8];

- with the exception of those solely operating in areas with 24 hours day light, ships shall be equipped with two remotely rotatable, narrow-beam search lights controllable from the bridge to provide lighting over an arc of 360 degrees, or other means to visually detect ice [7, 8];

- ships involved in operations with an icebreaker escort shall be equipped with a manually initiated flashing red light visible from astern to indicate when the ship is stopped. This light shall have a range of visibility of at least two nautical miles, and the horizontal and vertical arcs of visibility shall conform to the stern light specifications required by the International Regulations for Preventing Collisions at Sea $[7,8]$;

- for ships intended to operate in extended periods of darkness, searchlights suitable for continuous use to facilitate identification of ice shall be provided for each lifeboat [7, 8];

- masters, chief mates and officers in charge of a navigational watch on board ships operating in polar waters shall have completed training to attain the abilities that are appropriate to the capacity to be filled and duties and responsibilities to be taken up, taking into account the provisions of the STCW Convention and the STCW Code, as amended [7, 8];

- equipped with such means for removing ice as the Administration may require; for example, electrical and pneumatic devices, and/or special tools such as axes or wooden clubs for removing ice from bulwarks, rails and erections [7, 8].

Ships sailing in the polar waters shall increase the costs for satisfying the requirements of SOLAS amendments, as given in Table 5 .

Through the data collection from involved party of the costs, such as: the maritime safety administration, equipment suppliers, shipyard, etc., and maintenance for hull, machinery and equipment every 5 years, the additional cost is $\$ 32.6$ a day on average in 20 year period of ship service.

\section{Costs Analysis on Arctic NEP}

There are three parameters that will change if the general cargo ship decides to go via the NEP:

(1) The distance (which will affect total bunker consumption);

(2) The speed (expected speed reduction during NEP);

(3) The insurance costs.

Table 5 Increased costs of ships sailing on Arctic NEP by SOLAS Amendment (unite: \$).

\begin{tabular}{|l|l|}
\hline Hull and machinery(maintenance, every 5 years) & 200,000 \\
\hline Crew training & 3,000 \\
\hline Navigational equipment & 28,328 \\
\hline Communication equipment & 3,500 \\
\hline Life-saving \& Fire-fighting equipment and system & 2,840 \\
\hline Total & 237,668 \\
\hline Average (day, 20 year period) & 32.6 \\
\hline
\end{tabular}


For the moment the research will disregard icebreaker costs, as assuming that the NEP in the future may be navigated without icebreaker support. The research could include the additional cost of an ice-navigator, but this is a minor cost element in the big picture.

\subsection{Ship Yokohama-Hamburg via NEP}

The distance will depend on which route is taken through the NEP. Since the ship has a draught of 8 meters, the research will assume it will go the shortest route of 2,700 $\mathrm{nm}$ [9]. The total distance will then be $7,400 \mathrm{~nm}$, or a reduction of almost $35 \%$, as given in Table 6.

The research will assume that the average speed is reduced somewhat during the NEP to 12 knots on average. This will on the other hand reduce the fuel consumption on this leg. The research will further assume without any particular justification other than the assumption that although one could pass without icebreaker support, there might still be drift ice on this leg, so hull insurance will increase. The research just assumes it is tripled compared to the benchmark route. The results of these assumptions are summarized in Table 7.

It should be clear from Table 7 that the main savings from using the NEP are the reduction in fuel consumption in addition to cutting sailing time from 34 to 23 days. Fuel consumption is reduced by some $40 \%$. How much this is worth in US\$ will of course depend on the oil price.

Currently the price of low sulphur heavy fuel in Rotterdam is $\$ 169$ per ton, while diesel oil is $\$ 328$. With the much stricter regulations for sulphur contents in bunker oil coming into effect in 2020, it could be that in the future more ships will be using diesel fuel, which currently is $50 \%$ more expensive than heavy fuel. At the current price of $\$ 169$, the savings in our example is $\$ 58,305$ or more than 14 times the increased insurance costs in order of magnitude. In addition there come the savings of the Suez Canal toll of $\$ 51,168$,
Table 6 Distances in $\mathrm{nm}$ Yokohama-Hamburg via the NEP.

\begin{tabular}{|l|l|}
\hline Yokohama to the Bering Strait & 2,700 \\
\hline Bering Strait to Novaja Zemlja & 2,700 \\
\hline Novaja Zemlja to Hamburg & 2,000 \\
\hline Total & 7,400 \\
\hline
\end{tabular}

Table 7 General cargo ship Yokohama-Hamburg via the NEP.

\begin{tabular}{|l|l|}
\hline Distance NEP in nm & 2,700 \\
\hline Distance outside NEP in nm & 4,700 \\
\hline Speed in NEP in knots & 12 \\
\hline Speed outside NEP in knots & 14 \\
\hline Fuel consumption at 12 knots tons/day & 15.5 \\
\hline Days in the NEP & 9 \\
\hline Days outside NEP & 14 \\
\hline Total days & 23 \\
\hline Fuel consumption in the NEP in tons & 135 \\
\hline Fuel outside NEP in tons & 344 \\
\hline Total fuel consumption in tons & 479 \\
\hline Fuel consumption reduction in tons & 345 \\
\hline Increased insurance costs in \$ & 4,160 \\
\hline Increased costs by SOLAS amendment (\$) & 750 \\
\hline Saved Suez canal toll (\$) & 51,168 \\
\hline
\end{tabular}

so the total savings amount to about $\$ 109,473$.

Now the bunker prices are low, but the general sentiment is that they are more likely to be higher than today than lower.

The reduction in bunker consumption will also reduce emissions of $\mathrm{CO}_{2}$. More use of Arctic passages would, ceteris paribus, contribute to more sustainable transport.

A saving of around $\$ 109,473$ for a ship of almost $13,000 \mathrm{dwt}$ implies that the willingness to pay for icebreaker assistance is limited. A fee of $\$ 9$ or more per ton will cancel out the cost saving effect. The icebreaker fee for carrying mechanical engineering products (which seems relevant for this ship type) was $\$ 86$ in 2015. This is clearly unrealistic from a commercial point of view, as it would imply a cost almost twice that of the Suez Canal toll.

\subsection{Shanghai-Hamburg via NEP}

The research assumes the same sailing distance in the NEP of 2,700 $\mathrm{nm}$. In addition there comes the 
increased distance Shanghai to the Bering strait compared to Yokohama-Bering Strait of $814 \mathrm{~nm}$. The Arctic route is thus $8,214 \mathrm{~nm}$, or a reduction of $24 \%$.

There is no way a container ship can go through the NEP in 23 knots if there is any ice there at all, so the research assumes that the average speed through the NEP is 14 knots. This will substantially reduce the bunker consumption and the research has used the Admiralty formula (Fuel consumption $=\mathrm{k} *$ speed $^{3}$ ) to calculate the consumption.

The results are summarized in Table 8.

If the research again uses the March 2016 price of low sulphur heavy fuel oil of $\$ 169$ per ton, the fuel cost savings are $\$ 220,376$. The total cost savings for the container ship sums to $\$ 344,874$, or $\$ 81$ per container. The saving in sailing time is only 2 days, however.

It is assumed that a loaded container weighs 24 tons. If that were the case, our container ship would only be able to carry around 2,100 TEU or half its TEU capacity. If the research then, more realistically, assumes an average weight for a loaded container of 11 tons, our ship fully loaded would be willing to pay around \$7 per ton for eventual icebreaker assistance. The NSR Administration stipulated a fee for container cargo to \$43 per ton in 2015.

Table 8 Container ship Shanghai-Hamburg via the NEP.

\begin{tabular}{|l|l|}
\hline Distance NEP in nm & 2,700 \\
\hline Distance outside NEP in nm & 5,514 \\
\hline Speed in NEP in knots & 14 \\
\hline Speed outside NEP in knots & 23 \\
\hline Fuel consumption at 14 knots tons/day & 37.6 \\
\hline Days in the NEP & 8 \\
\hline Days outside NEP & 10 \\
\hline Total days & 18 \\
\hline Fuel consumption in the NEP in tons & 302 \\
\hline Fuel outside NEP in tons & 1,669 \\
\hline Total fuel consumption in tons & 1,971 \\
\hline Fuel consumption reduction in tons & 1,304 \\
\hline Increased insurance costs in \$ & 10,060 \\
\hline Increased costs by SOLAS amendment (\$) & 587 \\
\hline Saved Suez canal toll (\$) & 135,145 \\
\hline
\end{tabular}

\section{Conclusions}

The two dominant cost savings factors in the research are the fuel savings and the saved Suez Canal toll.

\subsection{Time Savings of General Ship Are Substantial by Using Arctic NEP}

Time savings of general ship are substantial by using Arctic NEP. A reduction in sailing time from 34 to 22 days will free up capacity that has a value for the ship owner as the ship can faster be put into new contracts. This value would have been explicit if the research had chosen a total yearly service approach. The value is difficult to stipulate, however, as it will totally depend on the actual market situation at the time of the sailing. Time savings could also have a value for the cargo owners. Commodities in transport tie up capital, which is an implicit cost for the cargo owners. For high value cargo, this cost element could be significant.

6.2 Fuel Savings of Container Ship Are Massive by Using Arctic NEP

Fuel savings of container ship are massive by using Arctic NEP. The reduction in fuel consumption implies a reduction in emissions of greenhouse gases and other substances [10]. Using the Arctic routes rather than the Suez route contributes to more sustainable transport networks, ceteris paribus. Emissions will be proportional to the actual fuel consumption. In a future where environmental concerns are more prominent, this is also an advantage that could be used commercially $[3,11]$.

\section{References}

[1] Wang, D., Li, Z. F., and Z, Y. 2014. Influence of Arctic Waterway Opening on China's Shipping Industry. Shanghai, CN: Navigation of China.

[2] Ho, J. 2010. "The Implications of Arctic Sea Ice Decline on Shipping.” Marine Policy: 713-5.

[3] Valsson, T., and Ulfarsson, G. F. 2011. "Future Changes in Activity Structures of the Globe under a Receding Arctic Ice Scenario.” Futures: 
450-9.

[4] Hong, N. 2012. "The Melting Arctic and Its Impact on China's Maritime Transport.” Research in Transportation Economics: 50-7.

[5] Li, Z. F. 2009. "Analysis of China's Strategy on Arctic Route.” China Soft Science: 1-7.

[6] Drewry. 2015. P142.

[7] IMO. 2014. SOLAS amendments.
[8] IMO. 2014. Adoption of the international code for ships operating in polar waters (POLAR CODE).

[9] China MSA. 2014. Guidelines on Arctic Navigation in the Northeast Route.

[10] IMO. 2010. MARPOL amendments.

[11] Grigentin, V. 2009. "Container Shipping on the Northern Sea Route.” International Journal of Production Economics. 